\title{
Small RNA Extraction using Fractionation Approach and Library Preparation for NGS Platform
}

\author{
Spandan Chaudhary ${ }^{*}$, Pooja S. Chaudhary ${ }^{2}$ and Toral A. Vaishnani ${ }^{3}$ \\ ${ }^{1}$ Department of Medical Genetics, Xcelris Labs Limited, Old Premchandnagar Road, Opp. Satyagrah Chhavani, Bodakdev, Ahmedabad-380015, Gujarat, India \\ ${ }^{2}$ NGS department, Xcelris Labs Limited, Old Premchandnagar Road, Opp. Satyagrah Chhavani, Bodakdev, Ahmedabad-380015, Gujarat, India \\ ${ }^{3}$ Bioinformatics department, Xcelris Labs Limited, Old Premchandnagar Road, Opp. Satyagrah Chhavani, Bodakdev, Ahmedabad-380015, Gujarat, India
}

Received: March 15, 2016; Accepted: April 04, 2016; Published: April 12, 2016

*Corresponding author: Dr. Spandan Chaudhary, Department of Medical Genetics, Xcelris Labs Limited, Old Premchandnagar Road, Opp. Satyagrah Chhavani, Bodakdev, Ahmedabad-380015, Gujarat, India, E-mail: spandan.chaudhary@gmail.com

\begin{abstract}
Small RNA isolation is a herculean task; it requires lots of standardization at each and every step. In present study, we have combined two protocols of total RNA isolation and standardized the protocol for small RNA isolation using flash page fractionation method. Due to difficulty in isolating high quality small RNA, most technologies use total RNA as a starting material for preparing small RNA library. Quality of both total and small RNA was determined using scientifically proven technology like Agilent bioanalyzer. In present study we have demonstrated a protocol for total and small RNA isolation from rice, followed by small RNA library preparation using Solid total RNA seq kit protocol for NGS platform (For SOLiD platform). Small RNA library was of good quality as per the parameters given in the protocol. We have validated the procedure four times which resulted good data, it concludes these procedures can be use to isolate high quality small RNA to be used for deep sequencing.
\end{abstract}

Keywords: miRNA; Small RNA; Flash page fractionators; Small RNA library; NGS; SOLiD

\section{Introduction}

Small RNA pairs with their target messenger RNA molecules and to suppress the gene expression in order to control the gene expression. miRNAs play a major role in cell proliferation, cell cycle, cell differentiation, metabolism, apoptosis, developmental timing, neuronal cell fate, neuronal gene expression, brain morphogenesis, muscle differentiation and stem cell division. The miRNAs are small, highly conserved RNA molecules that act as key regulators of development, cell proliferation, differentiation, and the cell cycle. Emerging evidence also implicates miRNAs in the pathogenesis of human diseases such as cancers, metabolic diseases, neurological disorders, infectious diseases and other illnesses [1-2]. Small RNAs have been classified into at least six groups, which are microRNAs (miRNAs), heterochromatic small interfering RNAs (hc-siRNAs), trans -acting small interfering RNAs (tasiRNAs), natural antisense small interfering RNAs (nat-siRNAs), repeat-associated small interfering RNAs (rasiRNAs), and in metazoans, the piwi-interacting RNAs (piRNAs) [3-7]. The active mature miRNAs are typically 21-24 nucleotides, single stranded RNA molecules expressed in eukaryotic cells. Small RNAs are 21-24 nucleotides in length and are known to play a major role in the activation of mRNAs and genomic DNAs [8]. 21-nucleotide microRNAs (miRNAs) and 24-nucleotide Pol IV-dependent small interfering RNAs (p4-siRNAs) are the most abundant types of small RNAs in angiosperms [9]. Some miRNAs are well conserved among different plant lineages; whereas others are less conserved, and it is not clear whether less-conserved miRNAs have the same functionality as the well conserved ones [1]. Recent whole genome sequencing data indicates that the 5'- and 3'- ends of miRNAs are variable, in which $5^{\prime}$ end is less variable than $3^{\prime}$ end [10]. These alternative length miRNAs are called isomers, and their biological function is unknown, miRNAs are known to affect the translation and/ or stability of the target messenger RNAs [11]. Each miRNA is believed to regulate multiple genes, and it is currently thought that greater than one third of all human genes may be regulated by miRNA molecules.

Small RNA was first discovered by David's Baulcombe's group at the Samsbury laboratory in Norwich, England, as a part of post transcriptional gene silencing in plants. RNA interference invariably leads to gene silencing via remodeling chromatin to thereby suppress transcription, degrading complementary miRNA or blocking protein translation [12]. Small RNAs are naturally produced as part of the RNA interference (RNAi) pathway by the enzyme dicer. SiRNAs are short double stranded RNA with 2 nucleotide overhangs on either end including a 5'phosphate group and a 3'- hydroxyl(-OH) group [13].

Rice is a staple food in India and a very important part of appetite of the entire world. It is one of the most important cereal and model monocot plant $[14,15]$. About three billion of the population depends on rice for their daily calorie needs [16]. Plenty of research work is going on and rice genome is also available, so it's comparatively easy to identify and study the siRNAs. There are two species: Oryza sativa and Oryza glaberrima, first being the most commonly grown throughout Asia, Australia, the Americas and Africa; and second species is grown on a small scale in western Africa [17]. In present study, 
we have standardized the protocol for small RNA extraction from 4 rice samples, suitable for downstream application like small RNA sequencing using next generation sequencing technologies like Miseq, NextSeq, HiSeq, Solid, Ion PGM etc. But, we have demonstrated the standardized protocol of preparing libraries for Solid analyzer. In any of the next generation platform for getting the best data from small RNA sequencing, quality of small RNA is very crucial criteria. Because of the complexity of the small RNA isolation protocols, Illumina is referring poly acryl amide gel based method to extract small RNA from adapter ligated total RNA [18].

Small RNA can be isolated from any tissue or plants directly using commercially available kits like mirVana ${ }^{\mathrm{TM}}$ miRNA Isolation Kit (Thermo scientific), miRNeasy Mini Kit (Qiagen) etc uses dual column based method in which small RNA is bound to second column. There is also a kit available which directly captures small RNA from tissue like mirPremier microRNA Isolation Kit (Sigma Aldrich). Common chemistry shared by all this kit is $\mathrm{pH}$ based binding of nucleic acid to the silica column and these columns are made to bind certain specific size of nucleic acids. On the other hand, flash PAGE Fractionator works on the principle of gel electrophoresis which isolates the molecules on the bases of the size which helps in efficient small RNA extraction. Column based methods isolate small RNA upto 200 nucleotides which captures data in deep sequencing technologies where as small RNAs like piRNA or siRNA are of 21-24 nucleotides long which are the desired target for any study, can be isolated precisely using flash page system.

\section{Materials and Methods}

\section{Sample collection}

Prior to the harvesting, juvenile leaves of rice were washed with DEPC (Diethylpyrocarbonate- D5758, Sigma ) treated water to remove surface contamination at sample collection site Jetalpur, Ahmedabad (Gujarat) India and were transported in TMS RNA stabilizer solution (XGgtms-100) with dry ice followed by storage at $-80^{\circ} \mathrm{C}$.

\section{Total RNA isolation}

Rice leaves were thawed at room temperature $100 \mathrm{mg}$ and and taken for RNA isolation using pure Link miRNA isolation kit (Invitrogen- cat. no. K1570-01) and pure Link RNA Micro kit (Invitrogen- cat. no. 12183-016) as per manufacturer's protocol. Further, combination of both these kit were used to get high quality and yield of total RNA. Total RNA isolation was done in triplicate using three different methods. Combination of both these kit's methods are as follow:

$100 \mathrm{mg}$ of plant leaves were grounded to fine powder in motor and pestle with liquid nitrogen. $300 \mu \mathrm{l}$ of binding buffer (L3) (supplied with miRNA isolation kit) was added to powder in mortar pestle and ground it gently to mix properly till it become complete homogenous solution. Lysate was centrifuged at 12000 $\mathrm{g}$ for 2 minutes at room temperature to remove any particular material. Supernatant was transferred to another sterile micro centrifuge tube and $300 \mu \mathrm{l}$ of $70 \%$ of ethanol was added to lysate and vortexed to mix well. Whole lysate volume $600 \mu \mathrm{l}$ was loaded on a new spin cartridge and centrifuged it at $12000 \mathrm{~g}$ for 1 minute at room temperature. $350 \mu \mathrm{l}$ of Wash Buffer I was added to spin cartridge and centrifuged at $12000 \mathrm{~g}$ for 15 seconds at room temperature and flow through was discarded. In a separate $0.2 \mathrm{ml}$ tube $70 \mu \mathrm{l}$ of DNase buffer and $20 \mu \mathrm{l}$ of DNase-I enzyme (Thermo scientific cat. no. ENO525) was taken (Total $80 \mu \mathrm{l}$ ) and mixed by pipetting and kept on ice. DNase I mixture $(80 \mu \mathrm{l})$ was added to the center of the cartridge and kept on ice for 15 minutes. After 15 minutes again $350 \mu \mathrm{l}$ of Wash Buffer I was added to the center of the spin cartridge and centrifuged at $12000 \mathrm{~g}$ for 15 seconds at room temperature and flow through was discarded. Spin cartridge was transferred to a clean RNA wash tube, provided with the kit and $500 \mu \mathrm{l}$ of Wash Buffer II with ethanol was added. Spin cartridge was centrifuged at $12000 \mathrm{~g}$ for 15 seconds at room temperature and flow through was discarded. Above two steps were repeated and spin cartridge was centrifuged at $12000 \mathrm{~g}$ for 1 minute at room temperature to dry the membrane. Collection tube was discarded and cartridge was inserted into RNA recovery tube supplied with the kit. $30 \mu \mathrm{l}$ of RNase-free water was added to the center of spin cartridge and incubated at room temperature for 1 minute then centrifuged for 2 minute at $\geq 12000 \mathrm{~g}$ at room temperature to elute the total RNA. Above step was repeated with $30 \mu \mathrm{l}$ of RNase- free water with same collection tube.

\section{Quantitative and qualitative determination of RNA}

Concentration and purity of total RNA samples were measured using the Nano Drop ND3.0 spectrophotometer (NanoDrop Technologies Inc, Wilmington, DE). For preparing $1 \%$ denaturing agarose gel, $0.5 \mathrm{~g}$ of agar powder was added to $50 \mathrm{ml}$ of DEPC treated water and boiled till it melted, followed by adding $8.75 \mathrm{ml}$ of formaldehyde and $5 \mathrm{ml}$ of $10 \mathrm{X}$ mops. Gel was run at 90 Volts for about 45 minutes (Figure 1). RNA integrity was assessed using nano chip on Agilent 2100 Bio analyzer (Agilent Technologies, Palo Alto, CA) (Figure 2). The gel image and bio analyzer profile with RIN value were analyzed to proceed with small RNA enrichment step.

\section{Small RNA enrichment}

Flash page fractionator (Ambion cat no.13100) (Figure 3) is a miniaturized version of poly acryl amide gel electrophoresis for isolating small RNA from total RNA samples. For the enrichment of small RNA using flash page fractionator system, four other materials are required.

1. Flash page Pre-Cast gel (Type A) (Cat no. 10010-ambion)

2. Flash page buffer kit (Type A) (Cat no. 9015- ambion)

3. ElectroZap ${ }^{\mathrm{TM}}$ Electrode Decontamination Solution (Cat \#9785)

4. Flash page Reaction Clean-up Kit (cat no.Am12200).

$60 \mu \mathrm{g}$ of high quality (RIN value above 6) total RNA was taken with loading buffer and dye, heat denatured and loaded onto the upper gel surface in the flash page fractionator, electrophoresed at $80 \mathrm{~V}$ constant voltage until the blue dye begins to exit the gel. As per manufacture's protocol this time should be around 12 


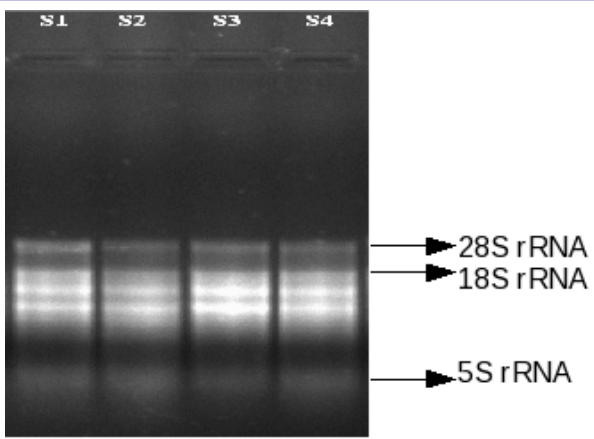

Figure 1: Agarose denaturing gel profile of total RNA isolated by combined pureLink miRNA isolation kit (invitrogen) and pureLink RNA Micro kit. Sample-1, 2, 3, 4 were loaded in lane 1, 2, 3, 4 respectively.
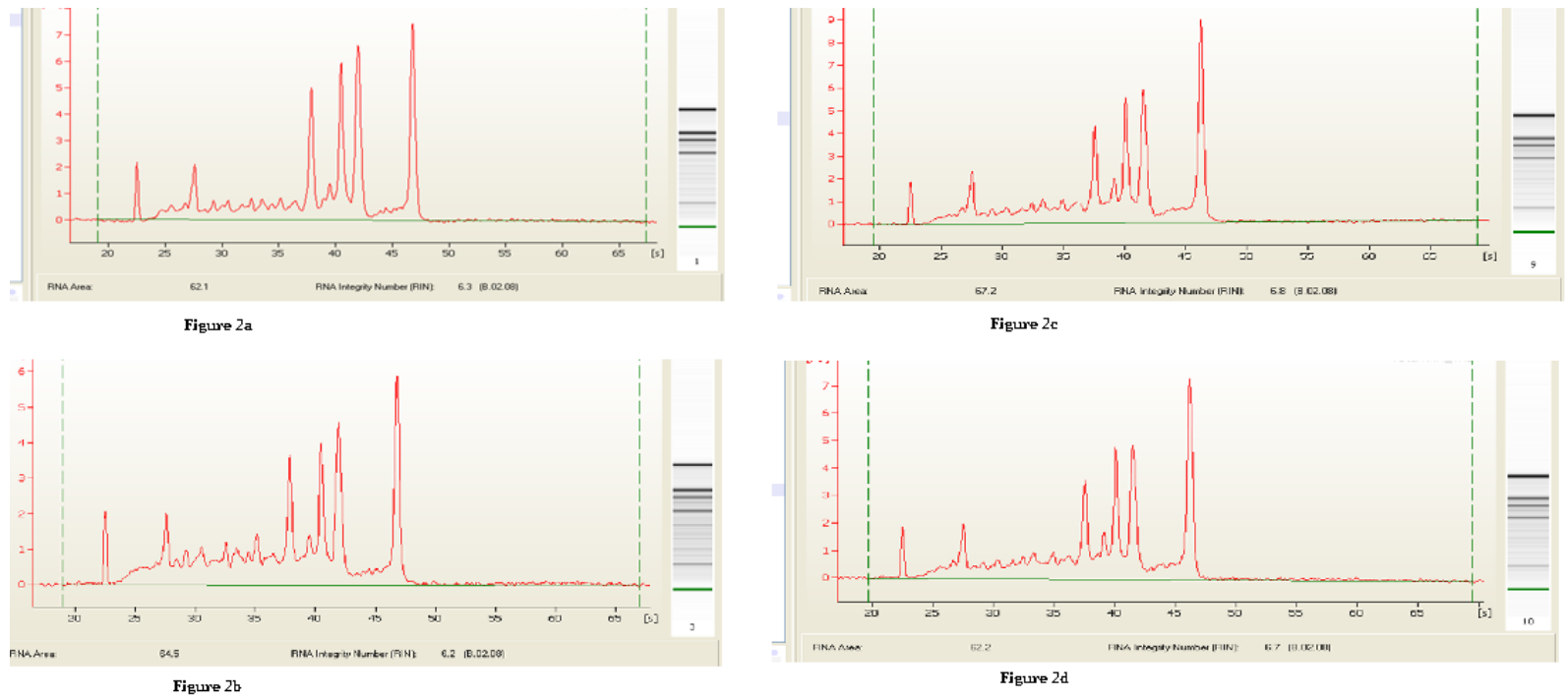

Figure 2: Total RNA profiling of samples 1, 2, 3 and 4 as figures 2a, 2b, c and 2d respectively, run on Agilent bioanalyzer nano chip.

minutes to obtain small RNAs with length of 15-140 nucleotides in the lower reservoir of the flash page system. As the selection of the small RNA is very important aspect of small RNA library preparation this step has also similar importance. The time described in the manufacturer protocol is mainly depends upon

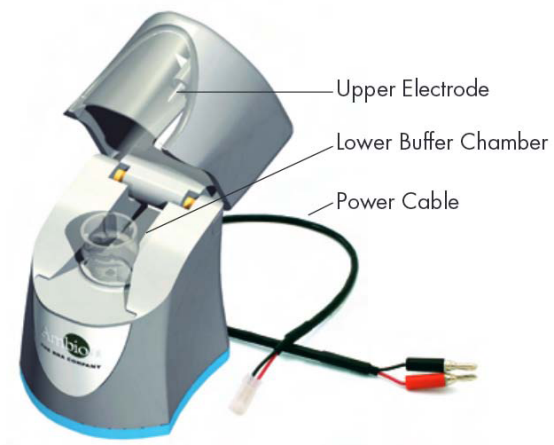

Figure 3: Flash page fractionator from Ambion (Thermo Fisher Scientific). the amount and quality of total RNA used, we had standardized the time for small RNA isolation is 13-14 minutes with the supplied pre-cast gels. The time required to obtain small RNA in the lower reservoir depend upon age of the pre-cast gel, as it is near to the expiry it will take more time which can be ranging from 12-15 minutes. Further, small RNAs were purified using flash page reaction clean-up kit (Ambion) as per manufacturer's protocol and small RNA profile was checked on Agilent 2100 bio analyzer using small RNA chips (cat no.5067-1548) (Figure 4). Handling of small RNA reagents for running on bio analyzer chip is difficult because it uses highly concentrated gel to separate small RNA fragments which are 21-24 nucleotides in length. Usually bioanalyzer protocols recommend use of filtered gel matrix within one month of time but it is not suitable with small RNA gel matrix. If stored gel matrix is used it will not detect the chip on bioanalyzer which was very usual case with small RNA chips the reason behind this is electrode cannot sense the gel matrix of the chip. To overcome this we used silica column (Nanosep centrifugal Devices with Omega Membrane, cat. no.29300-610) to prepare fresh gel matrix as agilent kit provides 

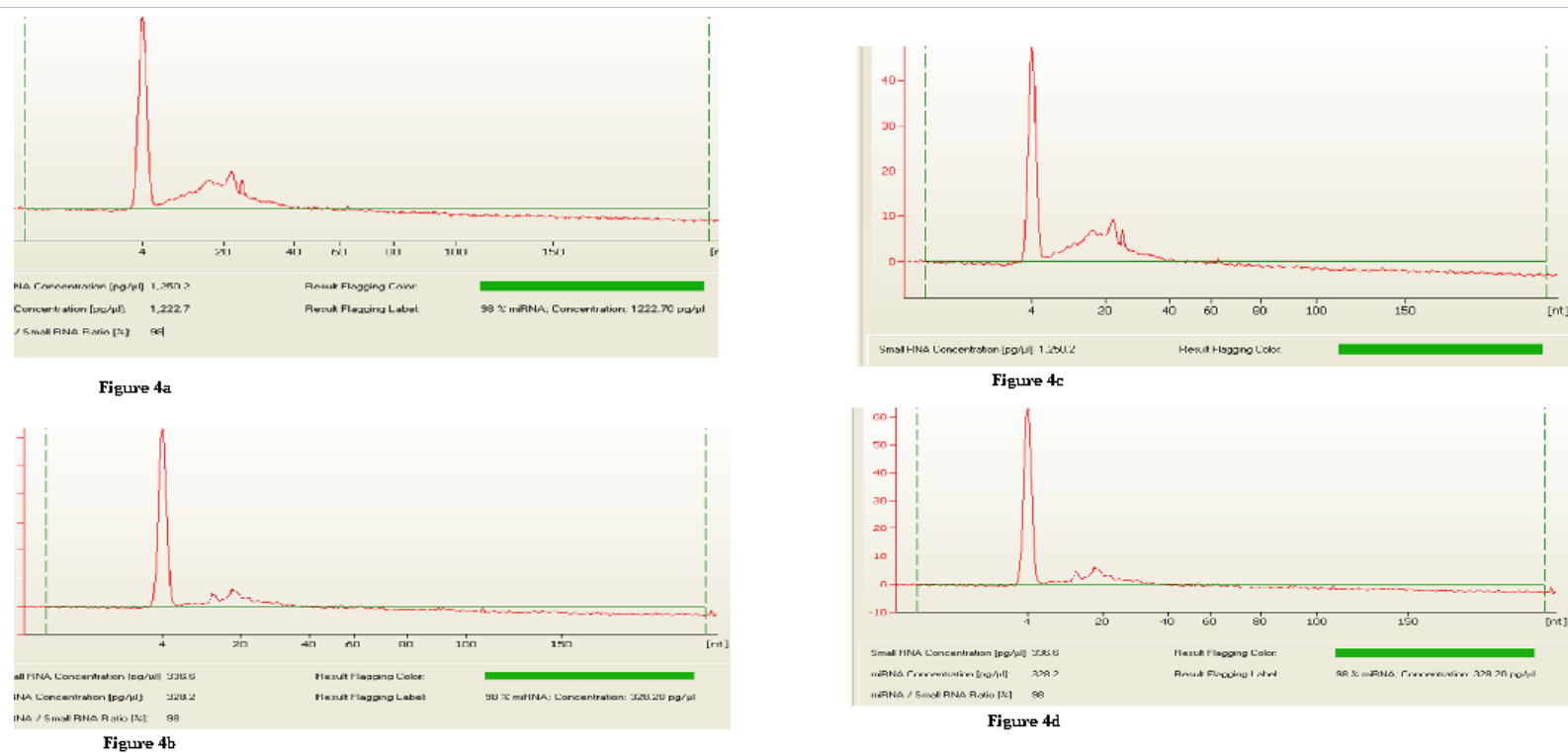

Figure 4: Small RNA profiling of samples 1, 2, 3 and 4 as figures 4a, 4b, 4c and 4d respectively, run on Agilent bioanalyzer small RNA chip.

two vials of gel matrix $650 \mu \mathrm{l}$ volume in each with two spin filters, however quantity is enough to run 25 chips. For preparing fresh gel matrix $45 \mu \mathrm{l}$ of gel was filtered each time through the column. Two micro liter dye (provided in the kit) was added to $40 \mu \mathrm{l}$ of filtered gel and rest protocol was followed as per manufacturer's instructions [19].

\section{Small RNA cDNA library preparation}

Small RNA cDNA library was prepared using Solid ${ }^{\mathrm{TM}}$ Total RNA-Seq Kit (Part Number 4452437 Rev. A 01/2010) [20] which involve five steps described as follows:

\section{Hybridization and adapter ligation}

The 5'- adapter ligation reaction was carried out in $20 \mu \mathrm{l}$ reaction containing 80-100 ng (as per nanodrop readings) of enriched small RNA in $3 \mu \mathrm{l}$ volume, $3 \mu$ hybridization solution, 2 $\mu \mathrm{l}$ solid adapter mix, $8 \mu \mathrm{l}$ of $2 \mathrm{X}$ ligation buffer and $2 \mu \mathrm{l}$ of ligation enzyme. Reaction mixture was incubated at 16 degree for $16 \mathrm{hrs}$ in a thermal cycler with heated lid open.

\section{RT-PCR of adapter ligated small RNAs}

After 16 hours of incubation, reverse transcription was carried out using $20 \mu \mathrm{l}$ reaction, containing $4 \mu \mathrm{l}$ 10X RT buffer, $2 \mu \mathrm{l}$ dNTP mixes, $2 \mu \mathrm{l}$ solid RT primer and $11 \mu \mathrm{l}$ nuclease free water. The reaction mixture was heat denatured at 70 degree for 5 minutes followed by snap chilling then $1 \mu \mathrm{l}$ array script reverse transcriptase enzyme was added in the reaction mixture and was incubated at 42 degree for 30 minutes resulting into the formation of single stranded cDNA followed by purification by using minelute PCR purification kit (Qiagen). The single stranded cDNA was quantified by using nanodrop 8000 spectrophotometer.

\section{Size selection for library preparation}

10\% TBE urea gel $1.0 \mathrm{mM}, 10$ wells (invitrogen cat
no.EC68752BOX) was used for size selection. Single stranded cDNA samples; 100ng of 10bp ladder (Cat no.10821015 invitrogen) at the concentration of $40 \mathrm{ng} / \mu \mathrm{l}$ was loaded in the gel. The gel was run in $\mathrm{x}$ cell sure lock mini cell gel assembly using $1 \mathrm{X}$ TBE running buffer at 180 volts for 47 minutes instead of 45 minutes recommended in the protocol. Gel was stained for 10 minutes with gentle agitation using syber gold nucleic acid gel stain. A continuous smear was seen in the SS cDNA well (Figure 5). The cycles for the in gel amplification would be determined on the basis of intensity of smear. Gel was cut horizontally between 60-80 nucleotides and gel slices was further cut vertically into 4 pieces of around $1 \mathrm{~mm}$ X $6 \mathrm{~mm}$ using clean blade. All four pieces of the gel slices were transferred to fresh $0.2 \mathrm{ml}$ RNAs free tubes.

\section{In Gel PCR amplification and purification}

Out Of four gel slices, $2^{\text {nd }}$ and $3^{\text {rd }}$ gel slices were used first for in gel PCR amplification. This $100 \mu \mathrm{l}$ reaction contains $10 \mu \mathrm{l}$ of PCR buffer, $8 \mu \mathrm{l} 2.5 \mathrm{~mm}$ dNTP, $2 \mu \mathrm{l}$ solid 5' primer, $2 \mu \mathrm{l}$ solid 3' primer, $1.2 \mu \mathrm{l}$ amplitaq DNA polymerase and $76.8 \mu \mathrm{l}$ nuclease free water and the gel slice as template DNA. 18 cycles of amplification was carried out and checked on E-gel 2\% size select gel (cat. no.G6610-02 Invitrogen).

\section{Quantification and qualification of cDNA library}

This cDNA library was purified using pure link PCR micro kit (Invitrogen) and further, quantified and qualified using 2100 bio analyzer with agilent high sensitivity (HS) DNA kit (cat no. 50674626) (Figure 6).

\section{Result and Discussion}

Ethanol precipitation method along with nucleic acid carrier such as glycogen is recommended for extracting total RNA with sizes of RNA having from $~ 20$ nt to several kilo bases in length. For RNA isolation, either reagent based or silica membrane 


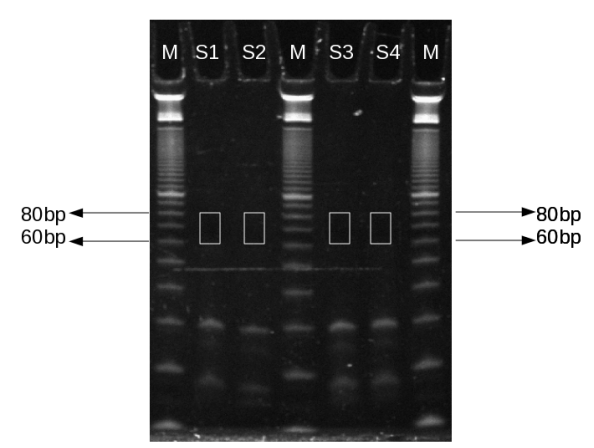

Figure 5: Gel image of size selection using10\% TBE urea gel $1.0 \mathrm{mM}, 10$ wells invitrogen cat no. EC68752 along with $10 \mathrm{bp}$ Invitrogen ladder in well labeled as M, samples are labeled as S1, S2, S3 and S4.
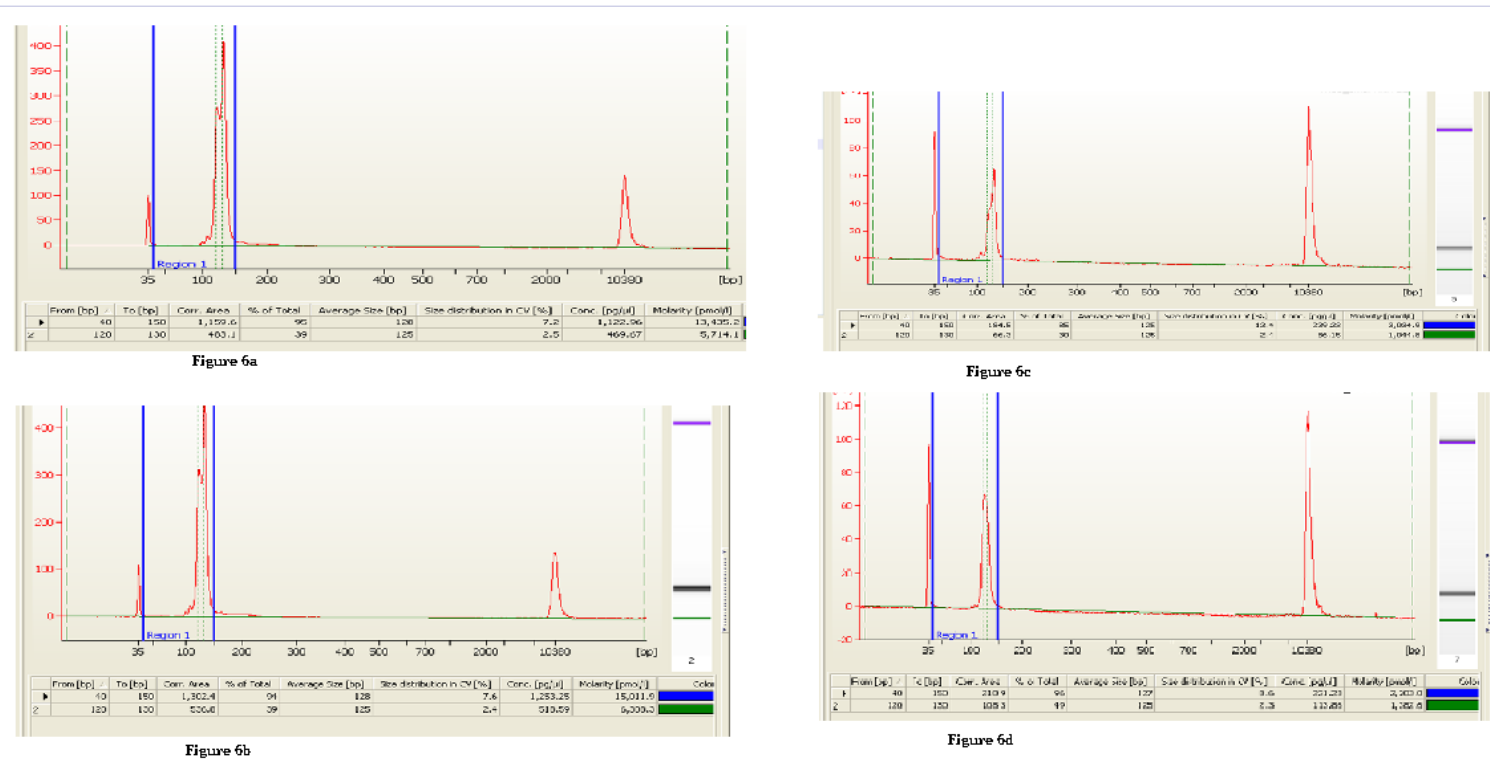

Figure 6: Small RNA library profile of samples 1, 2, 3 and 4 as figures $6 a, 6 b, 6 c$ and $6 \mathrm{~d}$ respectively, run using high sensitivity DNA chip on Agilent bioanalyzer.

based methods are generally used but it was found that small RNAs cannot be isolated using silica column based method instead trizol reagent based method is more suitable for the same [8], but we extracted total RNA using a modified silica column based method and isolated high quality total RNA with RIN value above 6, from this total RNA samples small RNA was isolated and checked on Agilent 2100 bioanalyzer. (Agilent Technologies, Santa Clara, Palo Alto, CA, USA). For getting good data by deep sequencing the most important parameter is the good quality library preparation which depends on the quality of total RNA and small RNA. RNA degradation during isolation procedure or loss of small RNA is the main reason for failure to obtain a good library. Absorbance $260 / 280$ ratio was found to be 1.9 , with the total yield of 90 micrograms, total RNA was loaded on $1 \%$ denaturing agarose gel, 2 distinct bands were observed, first band was of 28s rRNA and second band was of 18s rRNA (Figure 1). In Bio-analyzer profile, distinct peaks of $28 \mathrm{~s}$ and $18 \mathrm{~s}$ rRNA were visible along with a small peak near the lower marker indicating 5s rRNA region.

The quality of total RNA and selection of small RNA enrichment procedure play a momentous role in the small RNA cDNA library profiling. Total RNA having RIN value below 6 normally could not be used for small RNA enrichment, because such RNAs are found to be degraded. Several kits are available in the market that isolate small RNA directly from the tissues which don't require total RNA isolation to be done separately like Invitrogen miRNA isolation kit. But a drawback of this small RNA isolation method is that along with small RNA mRNAs and some other RNAs get also isolated which hinders in library preparation process and grab the data in the deep sequencing process. Flash page fractionators works as a vertical gel unit, it has negative electrode on the top and positive electrode at the bottom, RNA will migrate from upper side to the lower side. Same like normal gel electrophoresis principle, smaller fragments will migrate faster than the longer ones. When total RNA degradation occurs, 28s ribosomal RNA 18s ribosomal RNA band degrades 


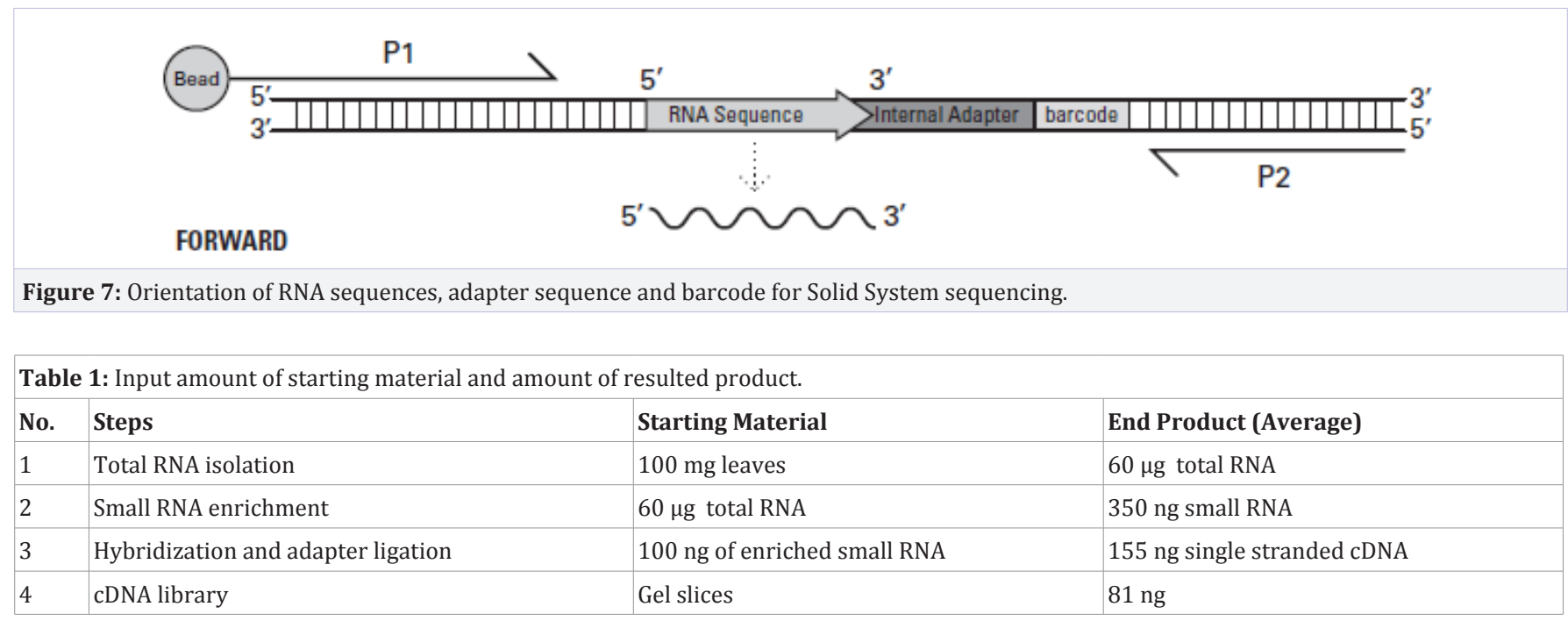

and produces small size ribosomal RNA fragments [21] which comes out with small RNA when pass through flash gel which ultimately leads to failure of the library or contamination of small RNA library with ribosomal reads. In order to avoid this, intact total RNA without any degradation is advised to use for preparing small RNA libraries even with flash page fractionators system.

NGS library preparation process requires optimization at each and every step from nucleic acid isolation to library quality check. Here, we have tried to provide the accurate data for how much starting material is required at each step and how much end product will be generated which is the principle missing point in all the available protocols, these will help the readers to repeat the same experiment. For small RNA enrichment by flash page fractionators, up to $100 \mu \mathrm{g}$ of high quality total RNA with RIN value of above 6 is advice. In present study, we started with $60 \mu \mathrm{g}$ of high quality total RNA having RIN value 6.2 to 6.8 , and after purification we obtained 350 ng of enriched small RNA. Small RNA profiles were analyzed using Agilent small RNA chip (shown in figure 4.) and the amount of small RNA was calculated and $100 \mathrm{ng}$ small RNA was taken for adapter ligation.

The RNA samples are hybridized and ligated with the adapters containing set of oligonucleotides with a single-stranded degenerate sequence at one end and defined sequence required sequencing at the other end. The adapters ligate in a manner that it provides template for sequencing from the $5^{\prime}$ end of the sense strand. The downstream emulsion PCR primer alignment and the resulting products of template bead preparation for Solid System sequencing are illustrated in (figure 7) Accurate size selection is very important for any library preparation for deep sequencing. Size selection was done using $10 \mathrm{bp}$ ladders as a reference; the gel was cut between 60-80 nucleotides. The insert length of the adapters is $18-38 \mathrm{bp}$, so the length of the amplified PCR product will be 110-130 bp but ideally small RNA library bands obtained within the range of $120-130 \mathrm{bp}$.

According to the protocol Solid TM Total RNA-Seq kit, criteria for small RNA cDNA library to be used for sequencing run depends upon the values obtained from the smear analysis done on DNA 1000 chip run. In present study we have used DNA High sensitivity chip so we modified the smear analysis criteria also. As per protocol, the library will be used for sequencing only if the ratio of $120-130 \mathrm{bp}$ area / 25-150 bp area is more than $50 \%$, if this ratio is less than $50 \%$, second round of size selection will be required. But as we have used high sensitivity chip, in which lower marker peak is at 35 bp instead of 15 bp in DNA 1000 chip, we have calculated the ratio 40-150 bp area. High sensitivity chip was used instead of DNA 1000 chip. In case of plants, it is very difficult to obtain small RNA libraries with $>50 \%$ ratio but in the present study we have achieved $52 \%$ ratio in one of our four samples.

\section{Conclusion}

Total RNA isolation protocol prepared by combining two different kits worked efficiently and provided high quality total RNA. Small RNA isolated from total RNA using flash page fractionator was of the good quality to be used for preparing small RNA libraries for all the NGS platforms. The libraries prepared by modified method were used for sequencing using Solid analyzer and generated good quality data (data not provided) which proves the modification applied at each stage of library preparation are acceptable.

\section{Acknowledgment}

Authors' are thankful to the management of Xcelris Labs for providing financial support.

\section{References}

1. Nobuta K, McCormick K, Nakano M, Meyers BC. Bioinformatics analysis of small RNAs in plants using next generation sequencing technologies." Methods Mol Biol. 2010;592:89-106. Doi: 10.1007/9781-60327-005-2_7.

2. Ha TY. MicroRNAs in human diseases: from cancer to cardiovascular disease. Immune Netw. 2011;11(3):135-54. Doi: 10.4110/ in.2011.11.3.135.

3. Hofmann NR. MicroRNA evolution in the genus Arabidopsis. Plant 
Cell. 2010;22(4):994. Doi: 10.1105/tpc.110.220411.

4. O’Donnell KA, Boeke JD. Mighty Piwis defend the germline against genome intruders. Cell. 2007;129(1):37-44.

5. Vazquez F, Vaucheret H, Rajagopalan R, Lepers C, Gasciolli V, Mallory $\mathrm{AC}$, et al. Endogenous trans-acting siRNAs regulate the accumulation of Arabidopsis mRNAs. Mol Cell. 2004;16(1):69-79.

6. Voinnet O. Origin, biogenesis, and activity of plant microRNAs. Cell. 2009;136(4):669-87. Doi: 10.1016/j.cell.2009.01.046.

7. Siomi H, Siomi MC. On the road to reading the RNA-interference code. Nature. 2009;457(7228):396-404. Doi: 10.1038/nature07754.

8. Lu C, Meyers BC, Green PJ. Construction of small RNA cDNA libraries for deep sequencing." Methods. 2007;43(2):110-7.

9. Ma Z, Coruh C, Axtell MJ. Arabidopsis lyrata small RNAs: transient MIRNA and small interfering RNA loci within the Arabidopsis genus. Plant Cell. 2010;22(4):1090-103. Doi: 10.1105/tpc.110.073882.

10. Nygaard S, Jacobsen A, Lindow M, Eriksen J, Balslev E, Flyger H, Identification and analysis of miRNAs in human breast cancer and teratoma samples using deep sequencing. BMC Med Genomics. 2009;2:35. Doi: 10.1186/1755-8794-2-35

11. Pillai RS. MicroRNA function: multiple mechanisms for a tiny RNA?. RNA. 2005;11(12):1753-61.

12. Ahmad, Parvaiz, and Saiema R, eds. Emerging Technologies and
Management of Crop Stress Tolerance: Volume 1-Biological Techniques. Vol. 1. Academic Press, 2014.

13. Chiu YL , Rana TM. siRNA function in RNAi: a chemical modification analysis." RNA. 2003;9(9):1034-48.

14. Goff SA, Ricke D, Lan TH, Presting G, Wang R, Dunn M, et al. A draft sequence of the rice genome (Oryza sativa L. ssp. japonica). Science. 2002;296(5565):92-100

15. Yu J, Hu S, Wang J, Wong GK, Li S, Liu B, et al. Adraft sequence of the rice genome (Oryza sativa L. ssp. indica). Science. 2002;296(5565):79-92.

16. Slayton T and Peter CT. Japan, China and Thailand can solve the rice crisis-But US Leadership is needed. Center for Global Development Notes. Accessed August 22: 2008. http://www.cgdev.org/files/16028_ file_Solve_the_Rice_Crisis_UPDATED.pdf

17. Israt Nadia, AKM Mohiuddin, Shahanaz Sultanaand, Jannatul Ferdous. Diversity analysis of indica rice accessions (Oryza sativa L.) using morphological and SSR markers. Annals of Biological Research, 2014;5 (11):20-31.

18. Truseq small RNA sample preparation guide, Catalog \# RS-930-1012 Part \# 15004197 Rev. A November 2010.

19. Agilent Small RNA Kit . Reorder number 5067-1548.

20. Solid ${ }^{\mathrm{TM}}$ Total RNA-Seq Kit. Part Number 4452437. Rev. A 01/2010.

21. Schroeder A, Mueller O, Stocker S, Salowsky R, Leiber M, Gassmann M, et al. The RIN: an RNA integrity number for assigning integrity values to RNA measurements." BMC Mol Biol. 2006;7:3. 